\title{
LAS MICROEMPRESAS EN TIEMPOS DE CRISIS: ANÁLISIS DE LA FORMACIÓN, LA EXPERIENCIA Y LA INNOVACIÓN
}

\author{
POR \\ Sonia BENITO HERNÁNDEZ ${ }^{1}$ y \\ Manuel PLATERO JAIME ${ }^{2}$
}

\section{RESUMEN}

España, al igual que Grecia, Portugal o Italia, es hoy en día uno de los países europeos con menos previsiones de crecimiento económico y con más tasa de paro de la Unión Europea. Su tejido empresarial, a diferencia de otros países como los nórdicos o centroeuropeos, viene caracterizado por el protagonismo de empresas de muy reducida dimensión con una media de 1-3 empleados. Estas empresas se caracterizan actualmente por el constante cierre de sus negocios y por la destrucción de empleo. Por este motivo, este trabajo pretende conocer cómo la crisis económica ha afectado a las microempresas y que factores han podido ser determinantes en su gestión. En concreto, se ha estudiado el caso español, extrapolable al resto de países mediterráneos, analizando las variables: formación, experiencia, antigüedad e innovación mediante un estudio empírico.

Palabras clave: microempresa, innovación, formación, antigüedad, crisis económica.

Claves Econlit: M130, L260, O310.

\footnotetext{
${ }^{1}$ Profesora del departamento de Economía y Valoración de la Escuela de Ingeniería Agrícola de la Universidad Politécnica de Madrid. Dirección para correspondencia: Universidad Politécnica de Madrid. Campus Ciudad Universitaria. Escuela de Ingeniería Agrícola. Edificio B. segunda planta. Dirección de correo electrónico: sonia.benito@upm.es

${ }^{2}$ Profesor del departamento de Economía de la Empresa de la Facultad de Ciencias Sociales de la Universidad Europea de Madrid. Dirección para correspondencia: Universidad Europea de Madrid. Campus de Villaviciosa de Odón. C.P. 28670 Villaviciosa de Odón. Madrid. Edificio A. Primera Planta. Dirección de correo electrónico: manuel.platero@uem.es
}

REVESCO No 108 - Segundo Cuatrimestre 2012 - ISSN: 1885-8031 - www.ucm.es/info/revesco

DOI: 10.5209/rev_REVE.2012.v18.39592

Fecha de recepción: 19/10/2011

Fecha de aceptación: 13/02/2012 


\title{
MICROENTERPRISES IN TIMES OF CRISIS: ANALYSIS OF THE TRAINING, EXPERIENCE AND INNOVATION
}

\begin{abstract}
Spain, as other countries like Greece, Portugal and Italy, is today one of the European countries with less economic growth forecasts and more unemployment of the European Union. Its companies, unlike the Nordic and Central European countries, are characterized by the prominence of small size companies with an average of 1-3 employees. These companies are currently characterized by the continued closure of their business and job losses. For this reason, this work aims to study how the economic crisis has affected micro-enterprises and what factors were decisive in their management. In particular we have studied the Spanish case, extrapolated to other Mediterranean countries, analyzing the variables: training, experience, age firm and innovation through an empirical study.
\end{abstract}

Keywords: micro-enterprise, innovation, training, firm age, economic crisis.

\section{INTRODUCCIÓN}

Los países mediterráneos europeos como Italia, Grecia, Portugal y España están inmersos en una crisis económica más acusada y con menos previsiones de crecimiento que los vecinos países centroeuropeos o nórdicos. Los expertos dicen, por ejemplo en el caso de España, que esta crisis está causada entre otros motivos por la dependencia de la economía de ciertos sectores que ahora se encuentran en una fase madura, como son el de la construcción, banca, automoción, etc., de los cuales dependen muchos puestos de trabajo (Tamames, 2009; Sampedro, 2009; Ortega Giménez, 2010). Si bien cada uno de estos países citados tiene peculiaridades diferentes en su estructura económica y en sus sistemas productivos, que determinan los resultados de cualquier efecto externo, se pueden encontrar también similitudes entre ellos. Una de estas características similares, sobre la que se va a trabajar en este estudio, es la composición de su tejido empresarial, en concreto, lo que se refiere al tamaño de sus empresas: mientras que en países como Austria, Irlanda, Luxemburgo y Holanda el tamaño medio de sus empresas es de 10 empleados, en Grecia, España o Italia lo es de 1-3 empleados. 
Esto podría no parecer importante si no fuera porque la supervivencia de las empresas en el mercado depende, de entre muchos otros factores, de su tamaño y porque además son las principales creadoras de empleo. Según la Federación Nacional de Asociaciones de Trabajadores Autónomos, en España en el año 2009, los trabajadores por cuenta propia representaban el 18,1 por ciento de los cotizantes. A un nivel similar se encuentra Chipre (17,8 por ciento), siendo superados estos porcentajes con creces países en como Grecia (30,2 por ciento), Italia (23,7 por ciento), Turquía (28,9 por ciento) y Portugal (23,2 por ciento). Las grandes empresas de banca, automoción, construcción crean empleo, pero las pequeñas lo hacen en mayor proporción, convirtiéndose en el motor de muchas de las economías de los países del sur de Europa.

En el caso español, desde finales del 2007 y hasta la actualidad la situación de recesión económica ha provocado la destrucción en términos absolutos de más de 9.282 microempresas, con sus consiguientes puestos de trabajo. Si se tiene en cuenta que desde el 31 de diciembre de 2005 hasta el 31 de diciembre de 2007 el número de microempresas creció en términos absolutos en $155.377^{3}$, parece necesario establecer una serie de mecanismos de ayuda para este tipo de empresas, protagonistas del tejido empresarial español y primeras víctimas de la situación económica actual.

Durante los últimos veinte años, cada vez más autores se han preocupado de analizar y estudiar a la pequeña y mediana empresa. Se han realizado estudios intentando establecer una relación entre la creación y destrucción de este tipo de empresas y otras variables económicas y sociales, situando este fenómeno en épocas recesivas y en épocas de crecimiento económico. Algunos trabajos publicados han mostrado la relación entre la aparición de nuevas empresas con épocas de bonanza económica (Davidsson, “et al”, 1994; Audretsch y Thurik, 2000); las oportunidades emprendedoras son los principales conductores del crecimiento según Wennekers, Van Stel y Thurik, 1999, con la innovación tecnológica y la renovación del tejido productivo (Reynolds, 1996) y con la reducción en el nivel de desempleo (Layard, R., Nickell, S. y Jackman, R, 1994). Otros, sin embargo, han contrapuesto la idea de la incidencia del desempleo en la creación de nuevas empresas. Los que argumentan la relación positiva entre el desempleo y el emprendimiento se basan en la idea de la aparición de un amplio conjunto de desempleados con aptitudes para convertirse en

\footnotetext{
${ }^{3}$ Datos del directorio de empresas (DIRCE) del Instituto Nacional de Estadística.
} 
empresarios (Audretsch y Thurik, 2000). Pero, desde una perspectiva global, una elevada tasa de desempleo puede influir negativamente en los niveles de creación de empresas, debido al descenso de las oportunidades de negocio que conlleva una economía en recesión o con bajas tasas de crecimiento.

La tasa de desempleo española es la más alta de la Unión Europea (según Eurostat la tasa de paro en abril de 2011 en España era del 20,7 por ciento) y, por este motivo, este estudio pretende analizar los efectos que está teniendo la recesión en las microempresas, principales contribuyentes a la creación de empleo. Existen factores que influyen en la gestión de la microempresa en épocas de crisis y que pueden ser la clave para que esta situación negativa pudiera ofrecerles alguna oportunidad de crecimiento en lugar de una amenaza a su supervivencia. En este trabajo se van a estudiar algunos de estos factores, en concreto; la innovación, la antigüedad, la formación y la experiencia.

En general, los empresarios en épocas de crisis suelen tener una sensación de dificultad para el desarrollo de los negocios, si bien depende del sector en el que actúen. Según estudios realizados como los del Informe GEM (2009) mediante una encuesta a 28.888 personas emprendedoras, resaltan que sí hay un porcentaje pequeño de empresarios que identifica oportunidades interesantes para sus negocios a pesar de la situación. En lo que sigue, se ha realizado un resumen de los datos obtenidos en este estudio, por el cual se pregunta a los microempresarios qué opinan sobre los efectos de la crisis. Se pueden resaltar los siguientes:

- El 48 por ciento piensa que es mucho más difícil crecer frente al 7 por ciento que piensa que es mucho más fácil.

- En comparación con las expectativas del año anterior, el 31 por ciento piensa que son mucho menores ahora, frente al 33 por ciento que percibe que son las mismas.

- El 45,3 por ciento piensan que tienen menos oportunidades en el mercado debido a la crisis.

Para conseguir el objetivo del estudio, en esta investigación se ha realizado una encuesta a microempresarios con preguntas sobre su gestión y características. Una vez realizada y para poder exponer los resultados y conclusiones obtenidas, se ha estructurado la investigación en una parte teórica y una empírica. En la parte teórica se ha realizado una 
revisión de la literatura, centrando el estudio en la formación, la antigüedad, la experiencia del microempresario y la innovación llevada a cabo por la microempresa.

La segunda parte se compone de un estudio empírico en el que, mediante un estudio de campo, se ha elaborado un modelo econométrico sencillo con el objetivo de estudiar las relaciones existentes entre estas variables citadas y el hecho de que la microempresa haya sido o no afectada negativamente por la crisis económica actual.

\section{LA FORMACIÓN Y LA EXPERIENCIA DEL EMPRESARIO EN LA GESTIÓN DE LA PEQUEÑA EMPRESA}

El nivel formativo de los directivos y empresarios tiene un efecto positivo sobre el rendimiento del capital humano de los trabajadores. La formación académica de quienes dirigen la empresa es un determinante positivo en la adopción de innovaciones que permite tener una mayor capacidad innovadora y, por tanto, una mayor capacidad para afrontar una crisis. (Levenburg, "et al”, 2006).) El capital humano, su nivel educativo, los conocimientos y las habilidades de que disponen las personas son un factor clave para la competitividad de una economía y, más en concreto, de una empresa en tiempos difíciles (Miller y Friesen, 1984)

En el 2009, el 62,6 por ciento de los empresarios en España eran hombres. La mayor proporción de hombres empresarios frente al de mujeres ha permanecido inalterable en los últimos años, si bien, en la actualidad, la crisis ha ampliado la diferencia existente entre ambos (Informe GEM, 2009). Con respecto a la formación, siguiendo los datos del mismo informe, el nivel educativo del empresario va mejorando cada año, puesto que se incrementa de un año a otro, siendo cada vez más las personas con estudios universitarios las que deciden crear una empresa.

Además, se puede observar en los datos expuestos por este informe un incremento en la incorporación de diplomados y formación profesional superior, en detrimento de los licenciados; la mayor proporción de este tipo de carreras comienza a notarse en el escenario emprendedor. El 59 por ciento de los empresarios según el informe GEM (2009) tienen estudios superiores. No obstante, estos datos pueden verse modificados a la baja en futuros 
años debido al incremento de empresarios inmigrantes que vienen sin estudios, (ya que los indicadores de emprendimiento inmigrante no europeo se han más que triplicado)

A pesar del incremento del nivel de estudios experimentado en los empresarios en los últimos años, España sigue estando por debajo de la Unión Europea que sitúa en el 77,6 por ciento el nivel de aquellos emprendedores que al menos han cursado bachillerato, según datos de la Confederación Española de Organizaciones Empresariales (CEOE, 2008). Sólo Portugal supera a España en datos negativos. El número de emprendedores españoles que, al menos, han acabado el bachillerato no llega al 60 por ciento. Los datos sobre los empresarios con un título universitario son igualmente negativos, aunque en este caso países como Grecia, Portugal o Italia están por debajo de España. El estudio publicado por la CEOE revela que este colectivo de formación superior apenas llega al 10 por ciento, siendo el 7,84 por ciento los que dirigen una empresa con asalariados que puede acreditar estudios superiores.

En cuanto a la experiencia del empresario, se va a tener en cuenta la edad de la persona como un indicador de experiencia general, para posteriormente estudiar los datos referentes a trabajos desempeñados como indicador de experiencia laboral. La edad puede reflejar aspectos relacionados con el capital humano que posea una persona (Kidd, 1993; Calvo y Wellisz, 1980). Así, la edad puede ser un indicador de experiencia y conocimiento (Álvarez Llorente y Otero Giráldez, 2007). Siguiendo los datos del Informe GEM (2009), hay que señalar que el 28,3 por ciento de los empresarios de las microempresas españoles tienen entre 35 y 44 años, el 21,5 por ciento tienen una edad superior a 44 años y el 50,3 por ciento tienen una edad inferior a 35 años, situándose la edad media en el año 2009 en 36,6 años (menor que la media de edad en el año 2005 que se situaba en 41 años). El rejuvenecimiento de la edad media del empresario se debe a dos motivos: la mayor incorporación de jóvenes al proceso de creación de una empresa (véase que uno de los posibles motivos es la elevada tasa de paro juvenil, mayor al 44 por ciento en España, según datos de Eurostat, 2010) y la mayor presencia de empresarios inmigrantes (suelen ser jóvenes) que quieren buscar un futuro en España, mediante la creación de empresas propias.

Dado que en este trabajo se estudia también la innovación de la microempresa, hay que señalar que trabajos publicados establecen que la edad del microempresario tiene una relación no lineal con la actividad emprendedora y la capacidad de innovación, según aumenta existe mayor propensión a la innovación, pero comienza a disminuir con los años por 
la pérdida de habilidades tecnológicas y la falta de adaptación al cambio, por lo que esta variable puede ser decisiva a la hora de afrontar una recesión económica (Aubert, "et al”., 2006; Verheul, “et al”., 2001).

En lo que a experiencia laboral se refiere, muchos de los empresarios que crean una empresa nueva cuentan con experiencia profesional previa, principalmente en un sector similar o relacionado y también en una función similar o relacionada. Fruto de esta mayor formación y experiencia, el empresario se mantiene cada vez más tiempo en el mismo cargo $\mathrm{y}$, por lo tanto, puede aumentar la probabilidad de éxito de la nueva empresa en épocas recesivas. Según algunos autores y estudios realizados, es importante señalar que la mujer microempresaria suele tener menos años de experiencia directiva y empresarial que los hombres antes de crear sus empresas (Marlow y Carter, 2004; Collins-Dodd, “et al”, 2004). Esto se debe, según estos trabajos, a que generalmente las empresarias crean su empresa después de pasada una edad (35-44 años), ya que dan prioridad a la constitución de una familia, adquiriendo experiencia en su propia empresa creada y no como empleadas asalariadas (Shim y Eastlick, 1998; Carter y otros, 2001; Informe GEM, 2009).

\section{LA INNOVACIÓN EN ÉPOCAS RECESIVAS DEL CICLO ECONÓMICO}

En su primera edición, el Manual de Oslo (Organización de Cooperación y Desarrollo Económicos, 1997) distinguía dos tipos de innovación: tecnológicas (actividades interconectadas de naturaleza científica, tecnológica, organizacional, financiera y comercial, cuyo objetivo común es la introducción de innovaciones en producto -bienes y servicios- o en proceso en el mercado) y no tecnológicas (cambios gerenciales, administrativos, organizacionales o en marketing que no están relacionados directamente con un proyecto de innovación tecnológica). Vinculaba la innovación de producto y proceso a las capacidades tecnológicas. Debido a la complejidad del proceso de la innovación y a su constante mejora de conocimiento, en su última edición (Organización de Cooperación y Desarrollo Económicos, 2005) el Manual de Oslo ha dado un paso adelante distinguiendo cuatro ámbitos en la innovación: producto, proceso, mercado y organización. En este trabajo se ha seguido este criterio, analizando en concreto 3 de los 4 ámbitos en los que una empresa puede innovar: producto, proceso y organización. 
Existen diferentes posturas cuando se abordan temas de innovación en períodos de crisis. Una de ellas defiende que en estos períodos es más difícil que las empresas, y más si son pequeñas, puedan innovar (Schumpeter, 1975; Kleinknecht, 1981; Cáceres Carrasco y Aceytuno Pérez, 2008).

Joseph Schumpeter introdujo dos ideas revolucionarias a las que denominó: destrucción creativa y acumulación creativa. La diferencia determinante entre estos dos conceptos es el papel y el tamaño de las empresas protagonistas de ambos fenómenos. En el proceso de destrucción creativa los protagonistas son los nuevos empresarios que juegan un papel fundamental en un mercado caracterizado por barreras de entrada bajas y por la creación de nuevas empresas, capaces de desplazar del mercado a las empresas menos productivas. Sin embargo, en el proceso de acumulación creativa, las protagonistas son las grandes empresas que interactúan en mercados con importantes barreras de entrada. Para Schumpeter, las nuevas empresas surgen en grupos o en racimos, impulsadas por las innovaciones, en medio de una lucha de lo nuevo contra lo viejo donde finalmente predominan las nuevas empresas con buenas ideas, impulsando el crecimiento económico por medio de la inversión capitalista. A este proceso de creación, constitución y mantenimiento de empresas de pequeña dimensión se le denomina microemprendimiento, (García- Gutiérrez Fernández, 1998).

Schumpeter (1939) también afirmó que las innovaciones en períodos de crisis son difíciles de aplicar porque las empresas aunque se encuentran motivadas para buscar innovaciones que les permitan ahorrar costes en sus procesos productivos, raramente se atreven a soportar el riesgo que conlleva la aplicación de una innovación en producto o similar (innovaciones radicales), dado que el sistema se encuentra en una situación de indeterminación y cambio que dificulta el cálculo de costes y beneficios, necesario para decidir sobre la introducción de una innovación.

Igual que Schumpeter, otros autores resaltan la posibilidad de que en épocas de recesión o depresión económica, las empresas no encuentren en la innovación una salida a sus problemas, sobre todo las pequeñas empresas, así Kleinknecht (1981) escribe sobre la necesidad de no sobreestimar la posible influencia de las recesiones macroeconómicas en la introducción de innovaciones, ya que los ciclos macroeconómicos no afectan en igual medida ni en el mismo momento a todas las ramas productivas. Las crisis macroeconómicas influirán 
con mayor intensidad en aquellas ramas de actividad con menor capacidad de adaptación a las innovaciones, considerando además que mientras algunas actividades se encuentran en recesión otras pueden vivir un momento de relativa prosperidad.

Investigaciones más recientes como la de Cáceres Carrasco y Aceytuno Pérez (2008) igualmente no han podido vincular la aparición de innovación en épocas de recesión señalando que: "La depresión económica puede ser un factor que impulse la búsqueda de innovaciones ya que, como se ha señalado, estimula a los empresarios a buscar alguna forma de reducir costes. Sin embargo, las investigaciones sobre esta materia no han demostrado fehacientemente la existencia de una relación entre depresión económica y aparición de innovaciones, mientras que la existencia de vínculos tecnológicos es generalmente aceptada".

Sin embargo, hay otra postura que sí que defiende la innovación en las pequeñas empresas en épocas recesivas, señalando que las épocas de crisis no deben suponer un freno a las actividades emprendedoras; sino más bien al contrario, ya que pueden surgir oportunidades de negocio tanto dentro de la empresa como fuera de ella (Nueno Iniesta, 2009). La innovación no tiene por qué suponer un elevado coste para la empresa, puesto que las innovaciones pueden surgir de una nueva forma de hacer publicidad o una nueva forma de trabajo que ahorre horas de suministros en la empresa. No necesariamente tiene porqué suponer un producto nuevo o mejorado técnicamente o en diseño, con los costes añadidos que esto supone (Shepherd y DeTienne, 2001; Ortega Gimenez, 2010).

La innovación para estos autores es su vía para crecer, sobrevivir y alcanzar el éxito (Jiménez Jiménez y Sanz Valle, 2006; Feeny y Rogers, 2003) y enfrentarse a su mayor vulnerabilidad frente a las amenazas del entorno por su reducida dimensión y sus limitados recursos (Covin y Slevin, 1989; Zahra y Pearce, 1994; Carrier, 1996; Schindehutte y Morris, 2001), ya que es en estas épocas, según argumentan, cuando el empresario se motiva más para encontrar mecanismos que le permitan ahorrar costes o captar liquidez mediante venta. Otros de los autores que defienden esta postura con algunas de sus citas se detallan en lo que sigue:

- Innovación mediante el capital humano de la empresa (formación, experiencia del mismo): los individuos que poseen conocimientos de las necesidades de los clientes pueden descubrir más oportunidades para la empresa, así como oportunidades con mayor potencial de crecimiento, más innovadoras (Shepherd y DeTienne, 2001) con la consiguiente mayor capacidad de creación de riqueza y bienestar social. 
- Innovación en la búsqueda de nuevos mercados: la captación de nuevos clientes es una forma de incrementar ventas, bien mediante la expansión geográfica de la actividad de la empresa (Ortega Giménez, 2010) o bien creando nuevas utilidades y adaptaciones a los productos de tal forma que puedan ser capaces de cautivar a nuevos clientes dentro de una misma población e incluso procedentes de empresas de la competencia. Es necesario tener una mentalidad abierta y creativa para poder aprovechar aquellas ideas que puedan incrementar el número de consumidores.

- Innovación organizativa mediante la creación de alianzas estratégicas como las las redes cooperación empresarial. Como se ha citado anteriormente, la supervivencia de las empresas en el mercado depende de muchos factores, entre ellos, como se ha citado anteriormente, el tamaño (Briones Peñalver,"et al”, 2010). Existe una relación positiva entre tamaño y probabilidad de supervivencia, de tal forma que la vía del crecimiento es la estrategia más efectiva para la conservación y estabilidad de las nuevas empresas, que buscan adaptarse lo más rápidamente posible a los cambios del entorno y que intentan conseguir una posición cada vez más estable dentro de su sector (Audretsch, 1991; Audretsch y Mahmood, 1991, 1995; Callejón y Segarra, 2000; Segarra y Arauzo., 2002, entre otros). Este es el motivo por el que muchos expertos recomienden a las pequeñas empresas que lleven a cabo estrategias de concentración, mediante redes de cooperación para que puedan ser más estables y competir mejor en el mercado (García Gutiérrez-Fernández, “et al”, 2006). Este tipo de estrategias de concentración pueden llegar a ser consideradas como actuaciones innovadoras de las microempresas dentro del área de la organización de las mismas, debido a la escasez de empresas que las realizan (Benito Hernández, 2009a).

En el caso de España, aunque la teoría es clara y conocida, en la práctica hay que tener en cuenta que las empresas españolas innovan bastante menos que sus homólogas europeas. Son muchos y diversos los factores que dan lugar a este hecho, entre los que se pueden citar (Dirección General de la Pequeña y Mediana Empresa, 2005):

- Sectores maduros menos proclives a la innovación.

- Empresas de menor tamaño a las europeas en general.

- Carencia de una cultura innovadora y espíritu emprendedor.

- Falta de cualificación del personal.

- Escasa capacidad de transferencia de conocimiento tecnológico. 
Aún a pesar de esto, según el Instituto Nacional de Estadística (INE), España ha incrementado de forma continuada los recursos dedicados a la $\mathrm{I}+\mathrm{D}$ en los últimos años:

- El gasto en I+D ha pasado del 0,91 por ciento del PIB en 2000 al 1,27 por ciento en 2007.

- El gasto en I+D por Comunidades y su estrategia de $\mathrm{I}+\mathrm{D}+\mathrm{i}$ ha sido muy desigual, marcada por las regiones, sectores dominantes y la estructura empresarial.

- El porcentaje de investigadores que desarrollan sus actividades en el sector empresarial se sitúa en un 34,5 por ciento (UE-27, 48,9 por ciento)

El Instituto de Estudios Económicos publicó en 2009 un trabajo que elaboró con los datos de la oficina estadística de la Comisión Europea (Eurostat) en el que se indicaba que España ocupaba la decimoséptima posición del ranking de gasto público en $\mathrm{I}+\mathrm{D}$ de la Unión Europea, por debajo de países como Estonia, República Checa y Portugal y de la media de la Unión Europea. Sólo el 18,3 por ciento de las empresas españolas lanzaron nuevos productos en el año 2006, una cifra que es un 43,5 por ciento inferior a la media de la Unión (32,4 por ciento).

España es, con una diferencia de más de seis puntos, el país en el que menos empresas innovan, por detrás de Rumanía (24,7 por ciento), Italia (29,5 por ciento y Portugal (29,8 por ciento). En este caso, Alemania (30,4 por ciento), Hungría (30,9 por ciento) y Reino Unido (31,6 por ciento) también se sitúan por debajo de la media comunitaria.

\section{METODOLOGÍA}

El presente trabajo pretende proporcionar un mayor conocimiento sobre los efectos que sufren las microempresas en épocas de crisis y sobre la influencia que puede tener la formación del empresario, su experiencia y la capacidad de innovación de la empresa.

El hecho de que una crisis o recesión económica afecte más o menos a una empresa o a otra depende de distintos factores y contextos que se pueden encontrar dentro y fuera de la empresa (Drucker, 1994). Los factores que pueden comprender aspectos de carácter interno se corresponden en muchas ocasiones con las características individuales del emprendedor y con los aspectos organizacionales de la empresa, aunque también con la experiencia de la misma ya que muchas de las capacidades que se valorarán y que le servirán serán derivadas de su 
antigüedad así como del capital humano (Guerras y Navas, 2009) el cual, en la actualidad, un $53,90^{4}$ por ciento de los casos lo formará el mismo microempresario, ya que se trata de empresas sin asalariados.

Por este motivo, se han elegido tres variables para analizar, dos de ellas, son la experiencia y la formación del microempresario, en concreto, se pretende conocer si:

- La edad del microempresario y, por tanto, su experiencia puede influye en si la crisis ha afectado o no a la microempresa.

- La antigüedad de la empresa en el mercado influyen en si la crisis ha afectado a la microempresa.

- El nivel de estudios del microempresario es un factor que intervenga en si la crisis ha afectado o no a la microempresa.

La última de las variables a analizar es la innovación realizada por la microempresa. Como se ha indicado en el epígrafe anterior, en este trabajo se ha querido analizar 3 de los 4 ámbitos en los que el Manual de Oslo (2005) aplica las distintas innovaciones en a empresa: producto, proceso y organización. La innovación en cada uno de estos ámbitos es muy amplia y de gran aplicabilidad para las empresas, por este motivo, se han elegido algunos de los indicadores más afines a la microempresa, en cuanto a sus posibilidades limitadas de innovación tanto en el desarrollo de nuevos productos, como en el uso de nuevas tecnologías así como en la innovación organizativa. Así pues, se pretende saber si:

- La innovación de la microempresa influye en si la crisis ha afectado o no a la microempresa, en concreto:

- El uso de la tecnología de la información y comunicación en la administración de la empresa puede ayudar a la microempresa en tiempos de crisis.

○ La pertenencia a redes u otras formas de cooperación empresarial ayuda a las microempresas en tiempos de crisis.

- El desarrollo de nuevos productos favorece a la microempresa en épocas de crisis.

\footnotetext{
${ }^{4}$ Datos del directorio de empresas del Instituto Nacional de Estadística (INE) a 11 de mayo del 2011. Datos del año 2010.
} 
Para poder alcanzar estos objetivos se han propuesto las siguientes hipótesis directamente relacionadas con los dos aspectos a analizar:

Con respecto al primer tema a analizar, la experiencia y la formación del microempresario:

- H1a: La crisis económica afecta menos a las microempresas cuanta más edad y, por tanto, mayor experiencia tengan sus microempresarios.

- H1b: La crisis económica afecta menos a las microempresas que tienen más antigüedad en el mercado.

- H1c: La crisis económica afecta menos a las microempresas cuanta más formación (enseñanza secundaria obligatoria, bachillerato, carrera universitaria...etc.) tengan sus empresarios.

Con respecto al carácter innovador de la microempresa:

- H2a: La crisis económica afecta menos a las microempresas si éstas utilizan tecnologías de la información y comunicación (innovación tecnológica para sus procesos de gestión)

- H2b: La crisis económica afecta menos a las microempresas si éstas realizan estrategias de concentración mediante redes u otras alianzas con empresas (innovación organizativa)

- H2c: La crisis económica afecta menos a las microempresas si éstas realizan estrategias de desarrollo de productos (innovación en productos)

\subsection{Variables}

En lo que sigue se detallan las variables que se van a analizar para poder alcanzar los objetivos propuestos en el estudio. En la tabla 1 se muestran las distintas variables con los indicadores, nomenclatura y valores que toman: 
Tabla 1. Resumen de variables para el estudio empírico.

\begin{tabular}{|c|c|c|c|c|c|}
\hline Tipo Variable & $\begin{array}{l}\text { Aspecto a } \\
\text { estudiar }\end{array}$ & Factor a valorar & $\begin{array}{c}\text { Variable } \\
\text { a } \\
\text { analizar }\end{array}$ & Nomenclatura & Valores \\
\hline Dependiente & $\begin{array}{l}\text { Afectación de } \\
\text { la crisis a la } \\
\text { microempresa }\end{array}$ & $\begin{array}{c}\text { Si ha afectado o no } \\
\text { la crisis a la } \\
\text { microempresa }\end{array}$ & $\begin{array}{l}\text { Afectaci } \\
\text { ón de la } \\
\text { crisis a la } \\
\text { microem } \\
\text { presa }\end{array}$ & CRI & $\begin{array}{l}\text { 0=La crisis no ha } \\
\text { afectado a la } \\
\text { microempresa. } \\
\text { 1=La crisis sí ha } \\
\text { afectado a la } \\
\text { microempresa. }\end{array}$ \\
\hline \multirow{6}{*}{ Independiente } & & $\begin{array}{c}\text { Edad del } \\
\text { microempresario }\end{array}$ & Edad & ED & Valores: 16-120. \\
\hline & $\begin{array}{c}\text { Edad- } \\
\text { Experiencia }\end{array}$ & Antigüedad & $\begin{array}{l}\text { Tiempo } \\
\text { de } \\
\text { permane } \\
\text { ncia en el } \\
\text { mercado }\end{array}$ & PERM & $\begin{array}{l}\text { Valores de 1- } \\
\text { infinito. }\end{array}$ \\
\hline & Formación & $\begin{array}{c}\text { Estudios o } \\
\text { formación reglados } \\
\text { del } \\
\text { microempresario }\end{array}$ & $\begin{array}{l}\text { Nivel de } \\
\text { estudios } \\
\text { alcanzad } \\
\text { o }\end{array}$ & EST & $\begin{array}{l}0=\text { sin estudios } \\
1=\text { estudios } \\
\text { básicos } \\
2=\text { estudios } \\
\text { secundarios } \\
3=\text { bachillerato } \\
\text { 4=formación de } \\
\text { grado medio. } \\
\text { 5=estudios } \\
\text { superiores } \\
6=\text { máster o } \\
\text { doctorado }\end{array}$ \\
\hline & \multirow{3}{*}{ Innovación } & $\begin{array}{c}\text { Innovación en } \\
\text { procesos }\end{array}$ & $\begin{array}{l}\text { Utilizaci } \\
\text { ón de } \\
\text { TIC } \\
\end{array}$ & TIC & $\begin{array}{l}0=\text { No utiliza } \\
\text { TIC. } \\
\text { 1=Sí utiliza TIC. }\end{array}$ \\
\hline & & $\begin{array}{c}\text { Pertenencia a redes } \\
\text { de cooperación o } \\
\text { otras estrategias de } \\
\text { concentración }\end{array}$ & $\begin{array}{l}\text { Pertenen } \\
\text { cia a } \\
\text { redes de } \\
\text { cooperac } \\
\text { ión o } \\
\text { otras } \\
\text { estrategia } \\
\text { s de } \\
\text { concentr } \\
\text { ación }\end{array}$ & RED & $\begin{array}{l}0=\text { No pertenece a } \\
\text { ninguna red de } \\
\text { cooperación. } \\
1=\text { Sí pertenece a } \\
\text { una red de } \\
\text { cooperación. }\end{array}$ \\
\hline & & $\begin{array}{l}\text { Desarrollo de } \\
\text { productos }\end{array}$ & $\begin{array}{c}\text { Desarroll } \\
\text { o de } \\
\text { nuevos } \\
\text { producto } \\
\mathrm{s}\end{array}$ & DESPRO & $\begin{array}{l}0=\text { No ha } \\
\text { desarrollado } \\
\text { nuevos } \\
\text { productos. } \\
\quad 1=\text { Sí ha } \\
\text { desarrollado } \\
\text { nuevos } \\
\text { productos. }\end{array}$ \\
\hline
\end{tabular}

Fuente: elaboración propia.

La justificación de las variables elegidas se puede explicar según la revisión bibliográfica realizada en la exposición teórica. En lo que sigue se hace un resumen de la misma: 
- La edad del microempresario puede ser un indicador de la experiencia que la persona tenga puesto que a mayor edad, mayor vida laboral, mayores competencias y habilidades desarrolladas (Aubert, “et al”., 2006; Verheul, “et al”., 2001).

- La formación académica ayuda a desarrollar la capacidad innovadora (Levenburg, "et al”., 2006). El nivel de desarrollo competencial y educativo del capital humano de una empresa es un factor clave para la competitividad de una economía en crisis (Miller y Friesen, 1984)

- La vida de la empresa y su permanencia en el mercado están relacionadas positivamente con la capacidad de innovación según argumentan algunos autores, por lo que se pretende saber si igualmente tienen también una relación, en este caso negativa, a la hora de afrontar una crisis (Díaz Díaz, “et al”., 2006; Jiménez Jiménez, “et al”., 2006).

- La cooperación empresarial e institucional en $I+D$, a través por ejemplo de redes de cooperación o pertenencia a grupos, favorece la innovación y la resistencia de las empresas en el mercado frente a los competidores. (Guzmán y Martínez, 2008, Solé Parellada y Bramanti, 2001, González Serrano, 2003).

- La utilización de la tecnología por parte de la empresa constituye un rasgo diferenciador en la intensidad de innovación. Las actividades de mayor intensidad tecnológica están muy relacionadas con los niveles mayores de innovación (Guzmán y Martínez, 2008). El buen manejo de la información puede significar la diferencia entre el éxito o el fracaso para los proyectos que se emprendan. Si la empresa tiene un buen sistema de gestión de la información puede lograr un alto nivel competitivo en el mercado y obtener mayor capacidad de desarrollo, (García-Gutiérrez Fernández, "et $a l$ ”, 2004). Diversos autores han puesto de manifiesto el papel desempeñado por las tecnologías de la información, en general, y por Internet en particular para mejorar la competitividad de las microempresas, reduciendo los costes de transacción entre actividades, disminuyendo el riesgo inherente a cada transacción (Bakos, 1991, pp. 295-310; Strader y Shaw, 1997, pp. 185-198), mejorando la eficiencia en las actividades de la cadena de valor y facilitando la difusión del conocimiento (Porter y Millar, 1985, pp. 149-160).

- El desarrollo de nuevos productos puede ayudar a la empresa a enfrentar situaciones difíciles de recesión o crisis (Nueno, 2009), atrayendo mediante éstos a nuevos clientes o creando así nuevas necesidades inexistentes hasta el momento. 


\subsection{Recogida de datos}

El estudio de campo realizado consiste en un análisis descriptivo y econométrico de la población a estudiar mediante una muestra elegida. Para la obtención de los datos se ha utilizado la técnica de la encuesta. La población a analizar son las 3,128.181 microempresas que formaban el tejido empresarial español a 31 de diciembre de $2009^{5}$.

La muestra inicial elegida fue de 400 empresas de menos de 10 empleados en el territorio nacional, las cuales ya participaron en un estudio previo sobre la contribución del microemprendimiento al desarrollo regional y sobre la formación de redes de cooperación empresarial, realizado en los años 2005-2007 (previos a la recesión económica). Según la ley de los grandes números de Bernuilli (Dunham, 1993), el número de elementos de la muestra sería de 400, para poblaciones infinitas (más de 100.000 elementos) con un valor de confianza del 95 por ciento y un margen de error del 0,5 por ciento, en el que la probabilidad a favor y en contra será del 50 por ciento, (Miguel Peris, 1997).

Sin embargo, debido a la crisis económica fundamentalmente, desde el año 2009 hasta el año 2010 que es cuando se ha vuelto a tratar la muestra para realizar este estudio, han desaparecido muchas de las microempresas con las que se trabajó inicialmente. En la tabla 2 se expone la modificación del número muestral y en la 3 el porcentaje de empresas desaparecidas por sectores de actividad:

Tabla 2. Delimitación de la muestra

\begin{tabular}{|c|c|}
\hline Total empresas muestra inicial (investigación 2005-2006) & 400 \\
\hline Total llamadas & 876 \\
\hline Empresas desaparecidas & \\
\hline La línea ya no existe & 149 \\
\hline No quieren participar en el estudio & 67 \\
\hline Entrevistas realizadas (investigación 2009-2010) & 36 \\
\hline
\end{tabular}

Fuente: elaboración propia.

\footnotetext{
${ }^{5}$ Datos del directorio de empresas del Instituto Nacional de Estadística a 31 de diciembre del 2009.

${ }^{6}$ Se incluyen en este apartado aquellas microempresas no localizadas existiendo línea de teléfono y las cesadas o liquidadas.
} 
Tabla 3. Comparativa empresas desaparecidas por sectores

\begin{tabular}{|c|c|c|}
\hline Sectores de actividad & $\begin{array}{c}\text { Muestra de 400 } \\
\text { empresas (años 2005- } \\
2006)\end{array}$ & $\begin{array}{c}\text { Muestra de 148 } \\
\text { empresas (años 2009- } \\
2010)\end{array}$ \\
\hline Servicios & 35,7 & 32,7 \\
\hline Distribución & 22,4 & 27,3 \\
\hline Industria & 9,2 & 10 \\
\hline Construcción & 16,5 & 9,3 \\
\hline Transporte & 6,5 & 8,7 \\
\hline Hostelería & 9,5 & 10,7 \\
\hline \multicolumn{2}{|c|}{ Fuente: elaboración propia. }
\end{tabular}

En la tabla 3 puede observarse la disminución en la muestra de las empresas relacionadas con los servicios pero sobre todo con la construcción. Por este motivo, se puede ver el incremento producido en otros sectores como la distribución o el transporte, permaneciendo similar la presencia de empresas de hostelería o industria.

A partir de la revisión de la literatura sobre las características y la gestión de las microempresas en épocas de crisis, se ha elaborado un cuestionario que consta de veintiséis preguntas cerradas. En el mismo se recogen algunos datos sobre las características de la microempresa como: el capital social de la microempresa en el momento de constitución, el número de asalariados, edad del microempresario, género, estudios, la forma jurídica, las perspectivas de futuro de la microempresa, pertenencia a redes...etc. Posteriormente, se pregunta sobre cómo la recesión económica ha afectado a la microempresa y, en caso de haberlo hecho, los efectos producidos en la oferta de productos, en resultados...etc., las estrategias llevadas a cabo, las actuaciones de responsabilidad social promovidas y otras preguntas relacionadas con el tema central del artículo.

Las encuestas se han realizado de forma personal y telefónica. Los teléfonos y otra información de contacto se ha obtenido utilizando la base de datos "Sistema de Análisis de Balances Ibéricos" $(S A B I)^{7}$. Las encuestas fueron respondidas siempre o bien por el microempresario o por un miembro trabajador de la empresa, familiar además del empresario (pareja o hijos). En la tabla 4 se ha realizado una ficha técnica del estudio.

\footnotetext{
${ }^{7}$ Base de datos sobre empresas privada de ámbito nacional y Portugal.
} 
Tabla 4. Ficha técnica del estudio de campo

\begin{tabular}{|l|l|}
\hline \multicolumn{2}{|l|}{ Población } \\
\hline Unidades de muestreo & Microempresas \\
Población total & $3,128.181$ \\
Tipo de población & Infinita \\
Elementos del muestreo & Microempresarios encuestados \\
Alcance & Nacional \\
Tiempo & Diciembre 2009 - junio 2010 \\
\hline Muestreo & \\
\hline Elección de las empresas a encuestar & Aleatoria \\
Tamaño muestral & 400 \\
Tipo de encuesta & Personales y telefónicas \\
Número de llamadas emitidas & 927 \\
Encuestas efectivas & 148 \\
Tasa de respuesta & $37 \%$ \\
\hline
\end{tabular}

Fuente: elaboración propia.

La elección sobre qué microempresas han sido encuestadas ha sido al azar, mediante una elección probabilística aleatoria simple. Cada elemento de la población tiene una probabilidad de selección conocida y equitativa (Malhotra, 2004). Una vez recogidas las respuestas de los cuestionarios se han organizado y registrado en una hoja de cálculo mediante la cual se ha realizado el análisis descriptivo.

A continuación se va realizar un analizar análisis descriptivo de la muestra mediante un estudio de frecuencias estadísticas. La finalidad es poder conocer la representatividad de ciertas características del microempresario y la microempresa en la muestra de empresas utilizada, interesantes para el estudio. Debido al tamaño de la muestra, se ha realizado una comparativa con otros estudios para poder analizar si los resultados de representatividad pueden ser aceptados. Para ello se ha elaborado una tabla resumen que recoge los siguientes datos: 
Tabla 5. Análisis descriptivo de la muestra

\begin{tabular}{|c|c|c|}
\hline \multicolumn{2}{|c|}{ Datos de representatividad de la muestra. } & $\begin{array}{l}\text { Comparativa con otros resultados, } \\
\text { según diferentes estudios realizados y }\end{array}$ \\
\hline Género del microempresario. & El 78 por ciento son varones. & $\begin{array}{c}\text { El 67,3 por ciento son } \\
\text { varones.(Informe GEM, 2009) }\end{array}$ \\
\hline Edad de microempresario. & $\begin{array}{c}\text { El } 73 \text { por ciento creó su } \\
\text { empresa con menos de } 40 \text { años. }\end{array}$ & $\begin{array}{c}\text { El 78,6 por ciento son menores de } 44 \\
\text { años. (Informe GEM, 2009) }\end{array}$ \\
\hline Estudios del microempresario. & $\begin{array}{l}\text { El } 53 \text { por ciento tiene estudios } \\
\text { superiores o bien carrera } \\
\text { universitaria o formación } \\
\text { profesional de grado superior. }\end{array}$ & $\begin{array}{l}\text { El } 59 \text { por ciento tiene estudios } \\
\text { superiores. (Informe GEM, 2009) }\end{array}$ \\
\hline $\begin{array}{c}\text { Permanencia de la empresa } \\
\text { en el mercado. }\end{array}$ & $\begin{array}{l}\text { El } 95 \text { por ciento llevan más de } \\
5 \text { años en el mercado. }\end{array}$ & $\begin{array}{c}\text { El } 87 \text { por ciento de las microempresas } \\
\text { encuestadas tiene entre } 4 \text { y } 20 \text { años de } \\
\text { vida (Benito Hernández y Ramos } \\
\text { Rodrigo, 2009a) }\end{array}$ \\
\hline Afectación crisis & $\begin{array}{c}\text { El } 78 \text { por ciento de los } \\
\text { encuestados se han visto } \\
\text { afectados por la crisis de forma } \\
\text { negativa. }\end{array}$ & $\begin{array}{l}\text { No hay datos comparables publicados } \\
\text { para las microempresas. Sí se han } \\
\text { encontrado datos fiables de } \\
\text { microempresas sin asalariados de las } \\
\text { cuales el } 88,6 \text { por ciento se han visto } \\
\text { afectadas por la crisis (CONAE, } \\
\text { 2010) }\end{array}$ \\
\hline $\begin{array}{l}\text { Problemas causados por la } \\
\text { recesión }\end{array}$ & $\begin{array}{c}\text { El } 74 \text { por ciento de los } \\
\text { encuestados han tenido } \\
\text { problemas por la disminución } \\
\text { de sus ventas. El } 29,7 \text { por } \\
\text { ciento han tenido problemas de } \\
\text { impagos. }\end{array}$ & $\begin{array}{c}\text { No hay datos comparables } \\
\text { publicados. Sí se han encontrado } \\
\text { datos sobre las oportunidades de } \\
\text { negocio de las microempresas las } \\
\text { cuales más del } 60 \text { por ciento vieron } \\
\text { disminuidas sus } \\
\text { oportunidades.(Informe GEM, 2009) }\end{array}$ \\
\hline Oferta de productos. & $\begin{array}{c}\text { El } 18 \text { por ciento de las } \\
\text { empresas han incrementado la } \\
\text { oferta (variedad) de sus } \\
\text { productos. Este porcentaje } \\
\text { llega al } 34 \text { por ciento en el caso } \\
\text { de las mujeres } \\
\text { microempresarias. } \\
\end{array}$ & $\begin{array}{l}\text { No hay datos comparables publicados } \\
\text { para las microempresas. Sí se han } \\
\text { encontrado datos sobre las } \\
\text { oportunidades de negocio de las } \\
\text { microempresas las cuales más del } 60 \\
\text { por ciento vieron disminuidas sus } \\
\text { oportunidades.(Informe GEM, 2009) }\end{array}$ \\
\hline $\begin{array}{l}\text { Estrategias de crecimiento } \\
\text { llevadas a cabo. }\end{array}$ & $\begin{array}{c}\text { El 70-81 por ciento de los } \\
\text { encuestados, dependiendo si } \\
\text { hablamos del análisis general o } \\
\text { del específico a } \\
\text { microempresarias dicen no } \\
\text { haber llevado a cabo ninguna } \\
\text { de las estrategias planteadas en } \\
\text { la pregunta } 9\end{array}$ & $\begin{array}{c}\text { No hay datos comparables publicados } \\
\text { para las microempresas. }\end{array}$ \\
\hline
\end{tabular}

Fuente: elaboración propia.

\footnotetext{
${ }^{8}$ No existe comparativa con el dato de 40 años.

${ }^{9}$ Las distintas estrategias planteadas en la pregunta fueron:

- Desarrollo geográfico de mercados

- Disminución del ámbito de actuación

- Alianzas estratégicas con otras empresas

- Descentralización de actividades

- Fusiones/absorciones

- Integración vertical

- Ninguna
} 
Una vez recopilados los datos mediante las encuestas realizadas, codificarlos en una hoja de cálculo y tratarlos mediante el programa estadístico "Soluciones Estadísticas de Productos y Servicios" (SPSS) se ha llevado a cabo un análisis de regresión logístico binario con el fin de observar la existencia de relaciones de dependencia entre la variable dependiente y cada una de las variables independientes propuestas. El motivo por el cual se ha recurrido a este tipo de análisis estadístico se debe a que en los casos en los que la variable dependiente es dicotómica como es el caso objeto de estudio, la mayoría de la literatura coincide en que la estimación de un modelo a través de un análisis de regresión OLS, puede inducir a problemas de sesgo e incluso, heterocedasticidad. Por esto se aconseja emplear una distribución simétrica (estándar o logística) y un estimador de máxima verosimilitud, tal y como sucede en los modelos de regresión logística binaria, (véase por ejemplo Burton, Cross y Rhodes, 2000, Elango, 2007) Así pues se ha recurrido a este modelo ya que es similar al análisis discriminante dos-grupos y presenta ventajas sobre esta técnica al ser más flexible (Hair , "et $a l ”, 1999)$. En el siguiente apartado se recogen los resultados obtenidos.

\section{RESULTADOS}

Las tablas 6, 7, 8 y 9 recogen respectivamente el resumen del modelo, la matriz de confusión, la matriz de correlaciones y los resultados obtenidos en el análisis de regresión logístico binario. El modelo obtenido fue significativo (Ji cuadrado=70,832 con 6 grados de libertad y $\mathrm{p}=0,000)$. Igualmente, el porcentaje de aciertos obtenido en el modelo es superior al 80 por cien, en concreto 89,9 por ciento.

Tabla 6. Resumen del modelo.

\begin{tabular}{|c|c|c|}
\hline $\begin{array}{c}-2 \text { log de la } \\
\text { verosimilitu } \\
d\end{array}$ & $\begin{array}{c}R \text { cuadrado } \\
\text { de Cox } y \\
\text { Snell }\end{array}$ & $\begin{array}{c}R \text { cuadrado } \\
\text { de } \\
\text { Nagelkerke }\end{array}$ \\
\hline 81,087 (a) & 0,380 & 0,593 \\
\hline
\end{tabular}

Nota: la estimación ha finalizado en el número de iteración 6 porque las estimaciones de los parámetros han cambiado en menos de,001.

Fuente: elaboración propia a partir de los resultados del programa SPSS. 
Tabla 7. Matriz de confusión

\begin{tabular}{|c|c|c|c|c|}
\hline \multirow{3}{*}{\multicolumn{2}{|c|}{ Observado }} & \multicolumn{3}{|c|}{ Pronosticado } \\
\hline & & \multicolumn{2}{|c|}{ Afectado crisis } & \multirow{2}{*}{$\begin{array}{c}\begin{array}{c}\text { Porcentaje } \\
\text { correcto }\end{array} \\
\text { no } \\
\end{array}$} \\
\hline & & No & Sí & \\
\hline \multirow[t]{2}{*}{ Afectado crisis } & $\mathrm{No}$ & 19 & 12 & 61,3 \\
\hline & Sí & 3 & 114 & 97,4 \\
\hline \multicolumn{4}{|c|}{ Porcentaje global } & 89,9 \\
\hline
\end{tabular}

Fuente: elaboración propia.

Tabla 8. Matriz de correlaciones

\begin{tabular}{|l|l|c|c|c|c|c|c|c|}
\hline \multicolumn{2}{|l|}{} & Constante & RED & ED & TIC & EST & DESPRO & PERM \\
\hline \multirow{4}{*}{$\begin{array}{l}\text { Variables } \\
\text { independientes }\end{array}$} & Constante & 1,000 & & & & & & \\
\cline { 2 - 10 } & RED & 0,268 & 1,000 & & & & & \\
\cline { 2 - 10 } & ED & $-0,098$ & $-0,333$ & 1,000 & & & & \\
\cline { 2 - 10 } & TIC & $-0,039$ & $-0,178$ & $-0,094$ & 1,000 & & & \\
\cline { 2 - 10 } & EST & $-0,664$ & $-0,341$ & $-0,061$ & $-0,150$ & 1,000 & & \\
\cline { 2 - 10 } & DESPRO & $-0,306$ & 0,009 & 0,152 & 0,016 & 0,053 & 1,000 & \\
\cline { 2 - 9 } & PERM & $-0,748$ & $-0,108$ & 0,061 & $-0,031$ & 0,097 & 0,194 & 1,000 \\
\hline
\end{tabular}

Fuente: elaboración propia a partir de los resultados del programa SPSS.

Tabla 9. Resultados obtenidos del modelo

\begin{tabular}{|l|l|c|c|c|c|c|c|}
\hline \multicolumn{2}{|c|}{} & Coef. Beta & Error Estándar & Wald & G.1. & P & Exp(B) \\
\hline Variables independientes & RED & $-0,116$ & 0,497 & 0,055 & 1 & 0,81 & 0,890 \\
\cline { 2 - 8 } & ED & $-1,370$ & 0,493 & 7,724 & 1 & 0,00 & 0,254 \\
\cline { 2 - 8 } & TIC & $-1,060$ & 0,440 & 5,799 & 1 & 0,01 & 0,347 \\
\cline { 2 - 8 } & EST & $-0,407$ & 0,238 & 2,929 & 1 & 0,08 & 0,665 \\
\cline { 2 - 9 } & DESPRO & $-0,737$ & 0,661 & 1,242 & 1 & 0,26 & 0,478 \\
\cline { 2 - 9 } & PERM & 0,196 & 1,261 & 0,024 & 1 & 0,87 & 1,216 \\
\cline { 2 - 9 } & Constante & 4,918 & 1,765 & 7,763 & 1 & 0,00 & 136,785 \\
\hline
\end{tabular}

Nota: Variable(s) introducida(s) en el paso 1: Red, Edad, Utilización TIC, Estudios, Innovación, Permanencia.

Fuente: elaboración propia a partir de los resultados del programa SPSS.

Puede observarse en los resultados de la tabla 9, que el coeficiente correspondiente a la edad del empresario y, por tanto, a la experiencia que pueda tener el mercado de trabajo, dentro del análisis de regresión binaria realizado indica que esta variable es significativa en el modelo propuesto con una confianza del 99 por ciento, por lo que la edad del empresario es una variable a tener en cuenta a la hora de explicar el hecho de que una microempresa pueda verse más o menos afectada por una crisis. Se acepta por este motivo la hipótesis H1a. El microempresario se identifica con la microempresa en muchos de los casos, no hay que 
olvidar que más de la mitad de las empresas que forman el tejido empresarial son empresarios individuales $\sin$ asalariados (53,90 por ciento según datos del Instituto Nacional de Estadística), por lo que no es extraño que la experiencia y saber hacer de éste influya de manera determinante en la trayectoria de la empresa. Por otra parte, hay que valorar la experiencia de éste como una variable positiva ya que cuanto mayor sea, mayores recursos y capacidades tendrá para poder afrontar una situación económica difícil.

En los resultados obtenidos en la tabla 9 se comprueba que el coeficiente correspondiente a la permanencia de la empresa en el mercado, por tanto, a la experiencia que pueda tener en el mismo, dentro del análisis de regresión binaria realizado, indica que esta variable no es significativa en el modelo propuesto, por lo que no parece que la experiencia en el mercado de la empresa sea una variable a tener en cuenta que pueda explicar el hecho de que una microempresa pueda verse más o menos afectada por una crisis o recesión económica, por lo que, se rechaza la hipótesis H1b. Si la experiencia del microempresario sí es significativa, no lo es tanto la de los años de permanencia de la microempresa en el mercado. Esto puede deberse a que puede haber microempresas que lleven pocos años pero que su propietario tenga una mucha experiencia y, por esto, tener mejores resultados que otras con mayores años de permanencia cuyos microempresarios son más nóveles.

La tercera hipótesis plantea los estudios del microempresario como una variable a tener en cuenta, en concreto esta variable hace referencia a la formación que pueda tener el microempresario. Como puede verse en los resultados del modelo, el coeficiente correspondiente a los estudios del microempresario dentro del análisis de regresión binaria realizado indica que esta variable es significativa en el modelo propuesto para un nivel de confianza del 90 por ciento, por lo que parece que la formación sí puede ser una variable a tener en cuenta a la hora de explicar el hecho de que una microempresa pueda verse más o menos afectada por una crisis o recesión económica, por lo tanto, este dato da soporte a la hipótesis H1c. Estos resultados son ratificados también por otros estudios citados anteriormente, como los de Zahra y Pearce (1994), que destacan el papel tan importante que ocupa la formación en el desarrollo e implantación de proyectos innovadores sobre todo en épocas de recesión.

Con respecto a la innovación, en concreto, mediante la utilización de TIC para la gestión de la microempresa, se verifica en la tabla de resultados obtenidos en la tabla 9 que el 
coeficiente correspondiente dentro del análisis de regresión binaria realizado indica que esta variable es significativa en el modelo propuesto para un nivel de confianza del 95 por ciento, por lo que parece que la utilización de tecnologías en la microempresa sí puede ser una variable a tener en cuenta a la hora de explicar el hecho de que una microempresa pueda verse más o menos afectada por una crisis económica, por lo tanto, se acepta la hipótesis H2a.

Según el informe de la Unión Internacional de las Telecomunicaciones ${ }^{10}$, las TIC no sólo han resistido a la crisis sino que desempeñan un papel clave en el crecimiento económico y la recuperación financiera mundial en todos los sectores comerciales e industriales, ya que ahorran costes significativamente y mejoran la productividad de las empresas. Otros estudios realizados muestran también el beneficio de la utilización de TIC en las microempresas de cara a la obtención rápida de información, cooperación con otras empresas y desarrollo de la innovación (Benito Hernández, 2009b, Rufino Moreno y Plaza Llorente, 2005, Gimeno, 2006)

En lo referente a la realización de estrategias de concentración y cooperación como mecanismos que permitan fortalecer a las microempresas en épocas recesivas del ciclo, se comprueba que el coeficiente correspondiente indica que esta variable no es significativa en el modelo propuesto. El hecho de realizar este tipo de estrategias por parte de las microempresas en el mercado no es un factor a tener en cuenta que pueda explicar el hecho de que una microempresa pueda verse más o menos afectada por una crisis o recesión económica, por lo tanto, se rechaza la hipótesis $\mathrm{H} 2 \mathrm{~b}$. Esto puede deberse a que en la práctica, en España, se hace escasa la utilización de las redes y otras formas de cooperación. Según el estudio realizado tan sólo el 5 por ciento de las microempresas encuestadas establece alianzas estratégicas con otras empresas. Otros estudios publicados avalan esta utilización mínima de este tipo de estrategias de cooperación por parte de las microempresas (Benito Hernández, 2009a, p.10, donde se indica que sólo el 7,75 por ciento de las microempresas en el estudio realizado formaban parte de redes de cooperación). Sin embargo, estudios internacionales si avalan la utilización de las relaciones de cooperación por parte de las PYMES, por ejemplo, para acceder a los mercados internacionales (Cullen, "et al", 2000; Carson, "et al”, 2006), tener la economías de escala (Masurel y Janszen, 1998), compartir conocimientos en innovación (Levy, Loebbecke y Powell, 2003) o para entrar a emprender en economías en transición (Fink y Kebler, 2010).

\footnotetext{
${ }^{10}$ Disponible en html en: http://www.itu.int/osg/csd/emerging trends/crisis/index.html
} 
En los resultados obtenidos en la tabla 9 se comprueba que el coeficiente correspondiente al desarrollo de nuevos productos por parte de las microempresas, en el análisis de regresión binaria realizado, indica que esta variable no es significativa en el modelo propuesto, por lo que no parece que el hecho de realizar este tipo de estrategias de innovación en producto por parte de las microempresas en el mercado, sea un factor a tener en cuenta que pueda explicar el hecho de que una microempresa pueda verse más o menos afectada por una crisis o recesión económica, por lo tanto, se rechaza la hipótesis H2c. La Encuesta sobre Innovación Tecnológica del Instituto Nacional de Estadística recoge los factores que dificultan o impiden la innovación en las empresas y se señala que el factor más importante es el desinterés y la desmotivación derivada por la crisis, pero también el coste que supone para una pequeña empresa. Shcumpeter (1975) ya indicaba, al igual que otros autores citados en este trabajo, que el desarrollo de productos para la pequeña empresa en épocas de crisis puede ser una estrategia demasiado costosa, por este motivo pocas veces llevada a la práctica. Por lo que este estudio parece avalar la primera postura de las dos expuestas en el epígrafe anterior.

\section{CONCLUSIONES, ÁREAS DE MEJORA Y FUTURAS LÍNEAS DE INVESTIGACIÓN}

La actual crisis económica está teniendo peores efectos en los países mediterráneos europeos que en los países nórdicos o centroeuropeos. Esto puede ser debido, entre otros factores, a la composición de su tejido empresarial, caracterizado por la existencia de empresas de muy reducido tamaño (1-3 empleados). Si se tiene en cuenta que el tamaño de las empresas es un factor importante para su supervivencia, puede que esto sea uno de los obstáculos para la recuperación en estos países, donde la destrucción de la pequeña empresa y por ende, de los puestos de trabajo que ésta crea, está a la orden del día.

En este trabajo, se ha estudiado el caso español como un ejemplo extrapolable a otros países como Grecia, Italia y Portugal, en concreto, se ha realizado un estudio empírico en el que se ha hecho un análisis especial sobre algunos de los factores que afectan a la gestión de la microempresaria en épocas de crisis, en particular se han estudiado variables que pueden definir la experiencia, la formación y la innovación en la microempresa. 
Hay que destacar que en el trabajo realizado, la mayoría de las empresas participantes se caracterizan por ser empresas consolidadas ya que llevan en el mercado más de 5 años, creadas en un 84 por ciento por personas menores de 40 años, y teniendo más del 53 por ciento estudios superiores.

En concreto, los resultados relativos a la representatividad de la muestra concluyen que el 78 por ciento de los microempresarios encuestados dicen haber sufrido de forma negativa los efectos de la crisis en sus empresas. El mayor problema causado por la crisis ha sido la disminución de las ventas (74 por ciento de los encuestados), seguido de los problemas de impagos por parte de clientes. Se vende poco y cuando se logra vender, en ocasiones, el cliente no paga.

Con respecto a las estrategias propuestas en el estudio, el 70 por ciento de los encuestados dice no haber llevado a cabo ninguna de las estrategias planteadas. Aun así, se pueden destacar dos estrategias de las descritas como las más representativas (17 y 18 por ciento respectivamente): desarrollo geográfico de mercados y reducción del ámbito de actuación. Con respecto a la estrategia de desarrollo de nuevos productos, sólo el 18 por ciento de las microempresas encuestadas han incrementado su oferta de productos (este dato, sin embargo, casi llega a duplicarse, llegando hasta el 34 por ciento si se analizan sólo las microempresas creadas y dirigidas por mujeres).

En lo relativo a los resultados obtenidos del modelo econométrico utilizado para poder estudiar la influencia de las variables elegidas; formación, innovación y experiencia en la afectación de la crisis a la microempresa se puede concluir que la edad del microempresario, la formación y la utilización de tecnologías de la comunicación y la información son variables a tener en cuenta en la gestión de la microempresa, ya que pueden influir a la hora de que ésta se pueda ver más o menos afectada por una situación económica recesiva.

Hay que señalar que más del 50 por ciento de las empresas del tejido empresarial español no tienen asalariados, por lo que se identifica microempresa y microempresario, y en esta situación la edad de éste es importante, siendo un indicador de experiencia y saber hacer. En cuando a la utilización de TIC, es igualmente significativa. La utilización de tecnologías en la gestión va ligada a la idea de ahorro de costes y mejora de la productividad. Por último, 
dentro de las variables a considerar hay que tener en cuenta la formación, la cual en épocas de recesión puede jugar un papel importante para llevar a cabo nuevos proyectos.

Hay que destacar también en las conclusiones del estudio econométrico realizado que la pertenencia a redes, el desarrollo de productos y la permanencia en el mercado por parte de la empresa no han resultado variables significativas. Éstas conclusiones pueden contraponer parte de la literatura escrita para la empresa mediana y grande, sin embargo, para la pequeña empresa, en concreto, la microempresa, siguiendo también otros estudios y publicaciones, son razonables ya que algunos autores citados en el texto avalan que el desarrollo de nuevos productos puede ser muy costoso y poco viable para las pequeñas empresas en épocas de crisis. Igualmente, la pequeña empresa no suele participar en redes de cooperación o en la creación de alianzas estratégicas, suelen trabajar de forma independiente.

Por último, la permanencia en el mercado no aparece en el modelo como una variable influyente, sin embargo, esto puede ser debido a que en el modelo, la muestra utilizada se caracteriza por ser estar formada como se ha indicado en párrafos anteriores, mayoritariamente, por empresas consolidadas y, por este motivo, este dato puede estar sesgado.

Este trabajo tiene claras áreas de mejora, entre ellas, incrementar del tamaño de la muestra y ampliar el estudio empírico a otros países como Portugal, Grecia o Italia. También se propone como área de mejora el estudio en profundidad de ratios financieros para poder trabajar de forma más cuantitativa y objetiva los efectos de la crisis en los resultados (ventas, rentabilidad económica, cuota de mercado, etc.) de las microempresas. Igualmente, puede intentar profundizarse en las variables de tal forma que puedan cuantificarse, como por ejemplo, cuantificar el gasto en investigación y desarrollo realizado por las microempresas estudiadas en estos años de crisis.

Por último, se debe señalar que estas áreas de mejora son motivo para futuras investigaciones que intentarán ampliar el estudio a otros países, realizando un análisis de los datos de forma más cuantitativa y ampliando el tamaño muestral. 


\section{BIBLIOGRAFÍA}

ÁLVAREZ LLORENTE, G. y OTERO GIRÁLDEZ, M.S. Características de los empresarios europeos: un análisis de sus diferencias y similitudes. Investigaciones Europeas de Dirección y Economía de la Empresa, 13(3), 2007, pp.147-159.

ANSOFF, I. Strategies for Diversification, Harvard Business Review, 35 (5), Sep-Oct, 1957 , pp.113-124.

AUBERT, P.; y, E. y Roger, M. New Technologies, Organisation and Age: Firm-Level Evidence, The Economic Journal, 116 (509), 2006, pp.73-93.

AUDRETSCH, D. B. New-Firm Survival and the Technological Regime, Review of Economics and Statistics, Inglaterra, MIT Press, 60, 1991, pp.441-450.

AUDRETSCH, D. B. y MAHMOOD, T. The Hazard Rate of New Establishments, Economics Letters, Suiza, 36 (2), 1991, pp.409-412.

AUDRETSCH, D. B. y MAHMOOD, T. New- Firm Survival: New Results using a Hazard Function, Review of Economics and Statistics, Inglaterra: MIT Press, 77, 1995, pp.97-103.

AUDRETSCH, D. y THURIK, A. Capitalism and democracy in the 21 st century: from the managed to the entrepreneurial economy, Journal of Evolutionary Economics, 10(1), 2000, pp.17-34.

BAKOS, J. Y. A strategic of Electronic market places, Management Information Systems, 15 (3), 1991, pp.295-310.

BENITO HERNÁNDEZ, S. El papel de las microempresas en el desarrollo económico regional: las redes de cooperación empresarial en España, Revista de Estudios Cooperativos (REVESCO),2009a, pp.31-59.

BENITO HERNÁNDEZ, S. Las redes de cooperación de microempresas en España y la utilización de TICs, CIRIEC España, Revista de economía social, pública y cooperativa, 64, 2009b, pp.59-84.

BODEN, R. J. y NUCCI, A.R. On the survival prospects of men's and women's new business ventures, Journal of Business Venturing, 2000, 15 (4), pp.347-362.

BRIONES PEÑALVER, "et al”. Visión estratégica y praxis de la cooperación empresarial, FISEC-Estrategias - Facultad de Ciencias Sociales de la Universidad Nacional de Lomas de Zamora, Año III, 6, Mesa VI, 2010, pp.86-107.

BURTON, F; CROSS, A.R y RODHES, M. Foreing market servicing strategies of UK franchisors: An empirical enquiry from a transaction cost perspective, Management International Review, 40 (4), 2000, pp.373-400. 
CÁCERES CARRASCO, F.R y Aceytuno Pérez, M.T. La innovación como fuente de oportunidades empresariales, Revista de Economía Mundial, 19, 2008, pp.136-156.

CALlEJÓN, M. y SEGARRA, A. Business Dynamics and Efficiency in Industries and Regions. The case of Spain, Small Business Economics, 13 (4), 1994, pp.253-271.

CALVO G. y WELLISZ, S. Technology, entrepreneurs and firm size, Quaterly Journal of Economics, 85, 1980, pp.663-678.

CARTER, S.; ANDERSON, S. y SHAW, E. Women business ownership: A review of the academic, popular and internet literature, Report to the Small Business Service, RR 002/01, 2001.

CARRIER, C. Intrapreneurship in large firms and SMEs: A comparative study, International Small Business Journal, 12 (3), 1994, pp. 54-62

COLLINS-DODD, C.; GORDON, I. M. y SMArt, C. Further evidence on the role of gender in financial performance, Journal of Small Business Management, 42 (4), 2004, pp.395417.

CONFEDERACIÓN DE AUTÓNOMOS Y MICROEMPRESAS. Estudio del perfil del colectivo del autónomo en España y su impacto en la economía, 2010, versión disponible en PDF en: http://www.conae.org/proyecto09/index.asp. (Consulta: 30 de mayo de 2011 y sucesivos)

CONFEDERACIÓN ESPAÑOLA DE ORGANIZACIONES EMPRESARIALES Boletín informativo marzo, 2008, información disponible en PDF en: http://www.ceoe.es/ceoe/contenidos.item.action?id=6793682\&menuId=5116155\&type=5 116155 (Consulta: 1 de junio de 2011 y posteriores)

COVIN, J.G. y SLEVIN, D.P. Strategic management of small firms in hostile and benign environments, Strategic Management Journal, 10(1), 1989, pp.75-87.

CULLEN, J.B., JOHNSON, J.L y SAKANO, T. Success through Commitment and Trust: The Soft Side of Strategic Alliance Management, Journal of World Business,35(3), 2000, pp.638-658.

DAVIDSSON, P.; LIDMARK, L. y OLOFSSON, C. New firm formation and regional development in Sweden, Regional Studies, 8(4), 1994, pp.395-410.

DÍAZ DÍAZ, N. L.; AGUIAR DÍAZ, I. y DE SAÁ PÉREZ, J. El Conocimiento Organizativo Tecnológico y la Capacidad de Innovación. Evidencia Para la Empresa Industrial Española, Cuadernos de Economía y Dirección de la Empresa, 27, 2006, pp.33-60

DIRECCIÓN GENERAL DE LA PEQUEÑA Y MEDIANA EMPRESA. La Innovación empresarial en España, 2005, disponible 
http://www.ipyme.org/NR/rdonlyres/3593719A-8B05-4C6C-AB46-

EF9A97CD5C88/0/innovacion2005.pdf. (Consulta 7 de mayo del 2010 y posteriores)

DRUCKER, P. Purposeful Innovation and the Seven Sources for Innovative Opportunity; en Innovation and Entrepreneurship: Practice and Principles, Cap. 2, Harper and Row, Nueva York, 1985, pp.30-36.

DUNHAM, W. Viaje a través de los genios, Editorial Pirámide, Madrid, Capítulos 8 y 9. 1993.

EUROSTAT. Tasas de desempleo en los países de la UE, 2011, información disponible en html

en:

http://epp.eurostat.ec.europa.eu/tgm/table.do?tab=table\&plugin=1\&language=en \&pcode =teilm020, (Consulta: 1 de junio de 2011 y posteriores)

FEDERACIÓN NACIONAL DE ASOCIACIONES DE TRABAJADORES AUTÓNOMOS. Datos sobre la representatividad del trabajo autónomo entre los cotizantes, 2009, información disponible en versión en: http://www.ata.es/imagenes/publicacionesPdf/publicacion31.pdf, (consulta: 1 de junio de 2011 y similares)

FEENY, S. y ROGERS, M. Innovation and Performance: Benchmarking Australian Firms, The Australian Economics Review, 36(3), 2003, pp.253-264.

FINK, M. y KEBLER, A. Cooperation, Trust and Performance: Empirical Results from Three Countries, British Journal of Management, 21 (2), 2010, pp.469-483

GARCÍA GUTIÉRREZ FERNÁNDEZ, C. El microemprendimiento y las empresas de participación, Revista de Estudios cooperativos (REVESCO), 65, 1998, pp.14-15.

GARCÍA GUTIÉRREZ FERNÁNDEZ, C., FERNANDEZ GUADAÑO, J., GARCÍA VILLALOBOS, J. C., MIRANDA FERNÁNDEZ, M. La red de información INTERNET de la sociedad de la comunicación y del conocimiento promueve la generalización de la participación en los procesos de tomas de decisiones, CIRIEC-España, Revista de economía Pública, Social y Cooperativa, 49, 2004, pp.31-54.

GARCÍA GUTIÉRREZ FERNÁNDEZ, C.; LEJARRIAGA PÉREZ DE LAS VACAS, G.R.; FERNÁNDEZ GUADAÑO, J; GÓMEZ APARICIO, J. Y MIRANDA GARCÍA, M. Las redes de Micro- organizaciones, 2006, documento que tiene su base en: www.ucm.es/info/ecfin3/Equipos de Trabajo/RMGS/, 2-188, (Consulta: 15 abril del 2010 y posteriores)

GIMENO, J. Las tecnologías de la información y la comunicación en las PYMES y otros avatares, Revista de Economía Industrial, 360, 2006, pp.77-92.

REVESCO N 108 - Segundo Cuatrimestre 2012 - ISSN: 1885-8031 - www.ucm.es/info/revesco 
GONZALEZ SERRANO, L. Cooperación y Empresas. Retos, presente y futuro, editorial Thomson,, Madrid, 2003, pp.61-64.

GUERRAS MARTÍN, L.A. y NAVAS LÓPEZ, J.E. La dirección estratégica de la empresa.Teoría y aplicaciones, Editorial Civitas Thomson, 2009, Madrid.

GUZMÁN, J. y MARTÍNEZ, J. A. Tipología de la innovación y perfiles empresariales. Una aplicación empírica, Economía Industrial, 368, 2008, pp.59-77

HAIR, J; “et al”. Análisis multivariante, $5^{\circ}$ edición, Editorial Prentice Hall International, 1999, Madrid.

INSTITUTO DE EMPRESA. Informe Ejecutivo GEM España, 2009, Información disponible

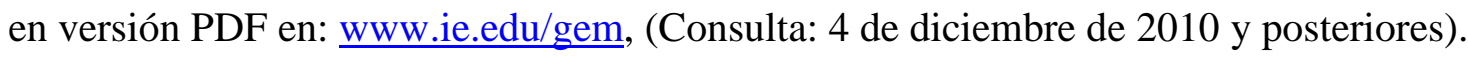

INSTITUTO DE ESTUDIOS ECONÓMICOS. Las empresas españolas ocupan el último lugar en innovación de productos, 2009, en publicaciones del Instituto, información disponible en: http://www.ieemadrid.es/modulo/upload/1_1261481993.pdf (Consulta: 2 de junio de 2009 y posteriores)

INSTITUTO NACIONAL DE ESTADÍSTICA. Directorio Central de Empresas, 2009,

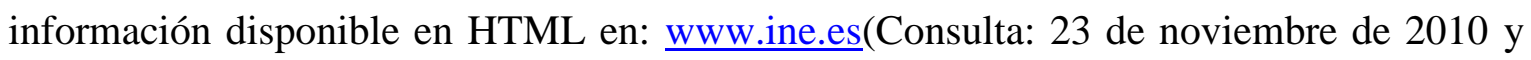
posteriores).

INSTITUTO NACIONAL DE ESTADÍSTICA. Datos extraídos de la Encuesta sobre Innovación Tecnológica en las Empresas, 2009, información disponible en: http://www.ine.es/jaxi/menu.do?type=pcaxis\&path=\%2Ft14/p061\&file=inebase \&L=0.

(Consulta: 7 junio de 2010 y posteriores)

JIMÉNEZ JIMÉNEZ, D. y SANZ VALLE, R. Innovación, Aprendizaje Organizativo y Resultados Empresariales. Un Estudio Empírico, Cuadernos de Economía y Dirección de Empresas, 29, 2006, pp.31-56.

KIDD, M. P. Immigrant wage differentials and the role of self-employment in Australia, Australian Economic Papers, 32, 1993, pp.92-115.

KLEINKNECHT, A. Observations on the Schumpeterian Swarming of Innovations, Futures, 13, 1981, pp.293-307.

LAYARD, R.; NICKELL, S. y JACKMAN, R. La crisis del paro, Alianza Editorial, 1994, Madrid.

LEVENBURG, N.; MAGAL, S. R. y KOSALGE, P. An Exploratory Investigation of Organizational Factors and e-Business Motivations Among SMFOEs in the US, Electronic Markets, 16(1), 2006, pp.70-84. 
LEVY, M., LOEBBECKE, C. y POWELL, P. SMEs, Co-opetition and Knowledge Sharing: The Role of Information System, European Journal of Information Systems, 12(1), 2003, pp.3-17.

MALHOTRA, N. K. Investigación de mercados. Un enfoque aplicado, Editorial Pearson Educación, Madrid, 2004, pp.365-376.

MARLOW, S. y CARTER, S. Accounting for change: Professional status, gender disadvantage and self-employment, Women in Management Review, 19(1), 2004, pp.5-16.

MASUREL, E. y JANSZEN, R. The Relationship between SME Cooperation and Market Concentration: Evidence from Small Retailers in the Netherlands, Journal of Small Business Management, 36(2), 1998, pp.68-74.

MIGUEL PERIS, S., “et al”. Investigación de mercados”, Editorial Mc Graw Hill, Madrid, 1997, p.151.

MILLER, D., FRIESEN, P.H. A longitudinal study of the corporate life cycle, Management Science, 30(10), 1984, pp.1161-1182

NUENO INIESTA, P. Emprendiendo: la destrucción creativa, Harvard Deusto business review, 181, 2004, pp.34-39.

ORGANIZACIÓN DE COOPERACIÓN Y DESARROLLO ECONÓMICO, (OCDE). Oslo Manual: Proposed Guidelines for Collecting and Interpreting Technological Innovation, 1997, Paris, OECD Publications.

ORGANIZACIÓN DE COOPERACIÓN Y DESARROLLO ECONÓMICO, (OCDE). Oslo Manual: Guidelines for Collecting and Interpreting Innovation, 2005, Paris, OECD Publications.

ORTEGA JIMÉNEZ, A. La internacionalización de la empresa española y la decisión de exportar como solución a la crisis, Revista sociales y jurídicas, 6, 2010, pp.88-111.

PORTER, M. E. Y MILLAR, V. E. How information gives you competitive advantage, Harvard Business Review, 64(4), 1985, pp.149-160.

REYNOLDS, P. New and small firms in expanding markets, Small Business Economics, 9, 1996, pp.79-84.

RUFÍN MORENO, R. y PLAZA LLORENTE, J.M. Un análisis de la influencia combinada de la capacidad comercial y de las tecnologías informativas (TIC) sobre las Pyme españolas innovadoras, Estadística Española, 47(160), 2005, pp.501-538

SAMPEDRO, J.L. Economía humanista. Algo más que cifras, Revista de Economía Mundial, 21, 2009, pp.283-287. 
SCHUMPETER, J.A. Capitalismo, socialismo y democracia, Nueva York: Harper, (publicado originalmente en 1942), 1975, pp.82-85.

SCHUMPETER, J.A. Business Cycles, 2 vols.,MCGraw Hill, New York, 1939.

SEGARRA, A. y ARAUZO, J. Las Barreras a la entrada de empresas: ¿Importa el tamaño?, Working Paper presentado en el V Encuentro de Economía Aplicada, 2002, Oviedo.

SCHINDEHUTTE, M. y MORRIS, M.H. Understanding strategic adaptation in small firms, International Journal of Entrepreneurial Behaviour \& Research, 7(3), 2001, pp.84-107.

SHEPHERD, D.A. y DETIENNE, D.R. Discoveryof Opportunities: Anomalies, Acumulation andAlertness, Frontiers of Entrepreneurship Research, 2001, información disponible en: http://www.babson.edu/, (Consulta: 3 de diciembre de 2010).

SHIM, S. y EASTLICK, M. A. Characteristics of Hispanic female business owners:an exploratory study, Journal of Small Business Management, 36(3), 1998, pp.18-35.

SOLÉ PARELLADA, F. y BRAMANTI, A. El porqué las redes de cooperación tecnológica,Quaderns de tecnología, 4, 2001, pp.114-117.

STRADER, T. y SHAW, M. J. Characteristic of Electronic Markets, Decision Support Systems, 21, 1997, pp.85-198.

TAMAMES, R. Para salir de la crisis global. Análisis y soluciones, Edita EDAF, 168-174, 2009, Madrid.

UNIÓN INTERNACIONAL DE LAS TELECOMUNICACIONES, información disponible en html en: http://www.itu.int/osg/csd/emerging trends/crisis/index.html. (Consulta: 3 de mayo de 2011 y sucesivos)

VERHEUL, I.; WENNEKERS, S.; AUDRETSCH, D. y THURIK, R. An Eclectic Theory of Entrepreneurship, Tinbergen Institute, Discussion Paper, TI 2001 - 030/3.

WENNEKERS, S. VAN STEL, A. y THURIK, R. (1999): Linking Entrepreneurship and Economic Growth, Small Business Economics, 13, 2001, pp.27-55

ZAHRA, S.A. y PEARCE, J.A. Corporate entrepreneurship in smaller firms: the role of environment, strategy and organization, Entrepreneurship, Innovation and Change, 3(1), 1994, pp.31-44. 